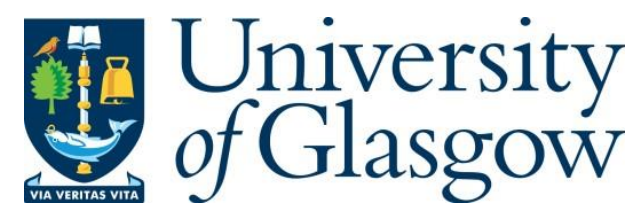

de Jong, A. and Varley, P. (2017) Food tourism policy: deconstructing boundaries of taste and class. Tourism Management, 60, pp. 212-222.

There may be differences between this version and the published version. You are advised to consult the publisher's version if you wish to cite from it.

http://eprints.gla.ac.uk/212474/

Deposited on: 31 March 2020

Enlighten - Research publications by members of the University of Glasgow http://eprints.gla.ac.uk 


\title{
Food tourism policy: deconstructing boundaries of taste and class
}

\author{
Anna de Jong and Peter Varley, Centre for Recreation and Tourism Research, University of the \\ Highlands and Islands, United Kingdom
}

\section{Journal: Tourism Management}

\begin{abstract}
Recent discussions from the journal of Tourism Management call for more critical deconstructions of the political and economic structures that shape policy and planning. This paper takes up this call, utilising a post-structualist framework to examine Scotland's food tourism landscape. Utilising Foucauldian discourse analysis to deconstruct 2,312 media sources collected through a Factiva database search, we illustrate the ways policy discourses privilege the cultural symbols of the middle class through official food tourism promotion, marginalising particular foods positioned as working class. We find that this is particularly evident through the example of the deep fried Mars bar; where, despite touristic desires, through classed media discourses it becomes constructed as global, bad and disgusting, and therefore an embarrassment to official tourism bodies. We conclude by discussing the broader importance of attending to the marginalising and silencing effects tourism policy exerts if the power values and interests involved in its formation are not critically appraised.
\end{abstract}

\section{Keywords}

Food tourism, class, tourism policy, disgust

\section{Highlights}

- Scotland's food tourism landscape is assessed using a post-structualist approach.

- We reveal policy privileges middle class symbols, marginalising working class.

- Food tourism policy is shown to overlook complexity of touristic desire.

- A case is made for further deconstruction of food tourism policy.

\section{Introduction}

Tourist studies is lacking in critical deconstructions of the political and economic structures that shape policy and planning. Greater engagement is required to understand the structures, values and interests that underpin such policy and planning (Dredge \& Jamal, 2015). Through examination of the deep fried Mars bar, this paper examines the ways Scotland's food tourism policy privileges the cultural symbols of particular groups, leading to the marginalisation of particular foods constructed as 'working class', whilst simultaneously failing to recognise the complexity of tourist encounters in constructing Scotland's culinary heritage. In interrogating the absence, distinction and governance directed towards Scotland's 'other' national dish - the deep fried Mars bar - we unpack the moral judgements drawn on that position this dish as 'bad' 'disgusting' and 'global' - in distinction to Scotland's 'good', 'local' larder. In unpacking complex characterisations of the deep fried Mars bar, we suggest that tourists seek much more complicated notions of Scottish food - which both trouble and reinscribe facile dualisms prevalent within policy media circulated discourses between good, local and desired food and bad, global and disgusting food. To that end, we argue that national food tourism policy often ignores the ways travellers' diverse gastronomic desires play an active role in making and remaking Scotland's rich and messy culinary heritage. As we will show, this active role is of importance because it offers opportunity for new corporeal connections that work beyond normative, fixed classed constructions. 
Rather than taking an objectionist approach which seeks to name, map and define what class is, we understand class to be in a constant process of becoming, where subjective experience, performance and discourse work to make and remake understandings of class in particular ways. We do not seek to suggest the deep fried Mars bar is predominately eaten by working class identifying individuals. Comparatively, we hope to illustrate the ways through which the deep fried Mars bar has become culturally associated as belonging to particular classed constructions derived through the entanglement of food, class and place. It is the deep fried Mars bar's cultural association with the 'unhealthy' diets of Scottish working classes, for example, rather than its ontological consumption by particular individuals, which we hope to illustrate has led to its absence, distinction and governance through Scotland's food tourism policy discourses. This is not the first scholarship to explore intersections of class, the deep fried Mars bar and Scotland. Rather we here build on the work of Knight (2016a, 2016b), in her examination of the ways the deep fried Mars bar is used as a public symbol to negotiate relations between Scottish national identity and the broader United Kingdom.

In examining the various ways through which the deep fried Mars bar is positioned within tourism policy discourses, and tourism discourses more broadly, this paper asks: what are the structures, values and interests influencing the positioning of this dish, and what are the effects and limitations of such positioning? In asking this question, we work to problematize the social factors and power processes influencing the ways through which food tourism has developed in Scotland. The paper begins by positioning Scotland's foodscape and policy approaches within broader Western trends towards local food systems. We here question the potentials of local food through exploring the ways alternative food systems are reliant on classed moral understandings in their construction. A second section outlines our use of Bourdieu's (1984) notions of cultural capital and distinction, before turning to an overview of methods in section three, as a process through which to understand the ways food, tourism and class intersect within the Scottish landscape. Turning to the discussion, the first two empirical sections illustrate how moral distinctions are drawn on to position Scotland's 'good', 'high-quality' produce as separate from Scotland's 'bad' deep fried food, and explore the ways forms of governance control touristic promotion of the deep fried Mars bar. The third empirical section works to complicate these characterisations through an examination of how tourists' abject desire for the deep fried Mars bar troubles hierarchical social constructions, presenting moments of normative transgression and cultural openness - whilst simultaneously reinforcing associations between deep fried Mars bars and working class bodies, in distinction to middle class ideals. Finally, we turn to reflect on the consequences for Scotland tourism policy and planning, and tourism management more broadly, in questioning these constructions.

\section{Contextualising food \& tourism policy}

In examining the construction of food tourism policy, it is crucial to recognise the processes through which local food advocacy has become mainstream in Scotland over the last few years. This has taken place through a number of specific actors and organisations, including but in no way limited to, the work of Nourish Scotland, Scotland Food \& Drink, Soil Association Scotland and newspaper journalists such as Cate Devine. Motivated by a variety of environmental, social, cultural and economic discourses - local food is thought to reduce food miles and greenhouse gas emissions, improve food safety and quality (resulting in greater health benefits), heighten social capital and bolster local economies (Campbell \& MacRae 2012, Seyfang 2006, Sherriff 2009 and Spence et al., 2009). Politically, support for small, local food producers is claimed as essential in resisting corporate power (Alkon, 2013). The entanglement of these multiple discourses are united through their distinction from globalised food systems. Understanding 'local as best' represents a desire to retain 
imagined pasts of idyllic, rural, non-capitalist systems (Halfacree, 2007). Through the construction of 'local as best', the global becomes framed as local's dichotomous Other. Globalisation serves as a threat to local gastronomic identities, as global signifiers are seen to infiltrate local landscapes (Mak et al., 2012). Here, the local becomes viewed as radical, subversive, sustainable; the global oppressive, hegemonic and unsustainable (Born \& Purcell, 2009 and Feagan, 2007). Forces of globalisation are thus viewed as threats to local cuisines - creating the homogenised effect of a 'global palate', and 'global cuisine' (Ritzer, 1995).

The touristic consumption of the deep fried Mars bar serves as a provocative case because it transcends facile distinctions between the global and local - despite its positioning as a global food. While not marketed as such, Mars bars are British in origin, their inception taking place in Berkshire, south east England in 1932. The Slough Industrial Estate in Berkshire claims to still manufacture the Mars bar today, however it is difficult to obtain figures indicating exact numbers of the chocolate bar manufactured within the United Kingdom. Mars sells products globally and moves production in response to economic markets. The deep fried Mars bar is said to have originated in Aberdeenshire, Scotland in 1992 (Williams, 2015). While distinctly 'local', Mars is also a recognisable international brand. It is one of the largest privately owned businesses, reaching sales of \$US33 billion in 2015.

Local food advocation has further exploded in response to highly publicised food scandals in recent years; generating discourses of trust, provenance and narratives of place as crucial. The 2013 horsemeat food adulteration scandal, in which processed beef products sold across Europe were found to be 'contaminated' with horsemeat, has perhaps been the most notable and affective (Dibb \& Fitzpatrick, 2014). While horsemeat is consumable, the scandal called into question the limits of trust and provenance when food production takes place elsewhere and supply chains straddle the globe (Abbots \& Cole, 2013). The scandal served as further fuel for local food advocacy, dramatically increasing consumer demand and trust in local food production (Staples \& Klein, 2016). Shorter food chains, thought to be representative of local food, generate heightened levels of trust, through apparently transparent provenance. This aspect is ironic as, in many ways, mass production generally tends to create assurances of reliable quality, whereas the variability of small-batch production is celebrated for its unpredictability. Through these understandings, place, as a moral imperative, becomes activated, as producers draw on simple narratives that position food within the landscape - a virtuous circle in which good consumers are connected with good producers and good places. Global distribution systems, by contrast, become tacitly labelled as bad, through their rendering as complex, placeless and unknown. This is despite the necessity of all food production having to take place somewhere, and all food systems narrating a process of production that skips the more viscerally abject moments (such as the moment of slaughter) in the telling of food journeys (Abbots \& Coles, 2013).

Class, likewise, plays a role in local food advocacy. Local food advocacy is often embedded within white, affluent and educated social privilege (Alkon, 2013). Local food strategies enacted by those of social privilege tend to be economic in focus - encouraging regional distribution models such as farmers' markets, local food festivals, and the more recent food assemblies, which effectively work to exclude those without the cultural capital, time or economic means to buy local (Alkon, 2013). Moreover, a crucial aspect of local food advocacy, as tied to middle class identity, relies on a perceived ability to 'taste place'. To distinguish place through taste relies on embodied knowledge, or embodied cultural capital, that enables individuals to distinguish 'good local food' from 'bad global food'; a process that works to enact a certain social positioning. Tourism is a crucial dimension in promoting understandings of the taste of place (Costa \& Besio, 2011); constructing a unique taste around a specific destination to localise and authenticate cuisine is a marketing strategy that has 
been utilised by restaurateurs since the nineteenth century (Spang, 2000). Paradoxically, the desires of middle class tourists to 'taste place', and the class differentiation that necessarily follows, are wrapped up in globalised gentrification processes, which bring into question facile dichotomies between local and global, good and bad. Dichotomies we seek to question in illustrating the classed moral judgements drawn on in the construction of discourses around Scottish food.

More broadly, increasing emphasis has been placed on food tourism over the previous decade, with the tasting of local food now recognised as an essential dimension of the touristic experience (Hjalager \& Richards, 2002 and Quan \& Wang, 2004). Much scholarship has thus focused on the motivations driving travellers to seek out culinary encounters when visiting certain destinations (Kim et al., 2009 and Yeoman at al., 2007) and the outcomes arising through such encounters - in terms of economic benefits and local development (Bessiere, 1998), attraction of and impediments to tourist experience (Cohen \& Avieli, 2004), alongside broader conceptualisation of the entanglements of food consumption and food experience (Mkono et al., 2013, Osman et al., 2014 and Quan \& Wang, 2004). Tourist scholars have focused particular attention on the ways culinary travel enables opportunity to encounter, and consume, Otherness (Mkono, 2011). During travel, food and eating are mobilised as material cosmopolitan symbols, through which consumption presents opportunity to both transgress and reinforce one's own cultural norms (Molz, 2007). The consumption of exotic, Othered foods, draws on long histories that position host-guest relations in particular ways; presenting both a moment of openness to cultural difference and transgression of culturally normative practice (Longhurst \& Johnston, 2016). This paper draws on these ideas through making sense of travellers encounters with the deep fried Mars bar, whilst visiting Scotland - a process, as we will show, that works to define both the visitor and the visited.

Our framing is influenced through the work of Everett (2009), who through similar agendas found negative perceptions of fried food in Newfoundland, Canada to be reliant on class based moral judgements. In her study, middle class judgements are bolstered by Western health discourses to support their own eating habits (represented through the absence of fried food), while those of the Newfoundland working class (understood as heavily reliant on deep frying methods), are positioned as unhealthy, low status and morally bad. Fried food is not only conceived as immoral for tourists to Newfoundland, it is understood as unclean or dirty - and therefore potentially dangerous (to health, for example) (Douglas, 1966). A crucial finding of this scholarship is that representations of deep fried food are dependent upon the spatial and cultural context within which they represent - rather than the materialities of the food itself. In the United Kingdom, by way of example, Japanese food is often conceived as healthy despite a similar reliance on deep frying in the preparation of dumplings, chicken katsu, tempura and so on (Booth, 2013 and McCurry, 2013).

Everett (2012), more recently, questioned the absence of seal flipper pie in tourism destination marketing material in Newfoundland, Canada. Seal flipper pie, Everett noted, is associated with poverty and desperation - the meat once being crucial to self-sufficiency in the harsh, peripheral environment. Seal flipper pie thus represents a certain stereotypical working class identity, associated with a perceived uneducated and environmentally unaware individual. Everett argues that seal flipper pie's absence from marketing material illustrates the ways destination marketers are in a constant negotiation between appealing to middle to upper class traveller expectations, whilst remaining relevant to their main, local customer base. What becomes elevated through the promotion of culinary tourism can be seen as a sign of prosperity, where those with the tools for expression and manipulation of social power are able to elevate particular foods to the realms of desire and recreation (Long, 2015). 
Whilst culinary tourism is increasingly utilised as a way to enhance sustainability and rural development by policy makers, critical deconstruction relating to the policy and planning dimensions of culinary tourism remain peripheral to tourist studies (Everett \& Aitchison, 2008). Notable exceptions include the work of Sims (2009), Everett and Slocum (2012), all of whom have examined the role of food tourism in delivering policy agendas relating to social, economic and environmental sustainability. Their work cautions against overstating the potentials of food tourism as a way through which to enhance sustainability, highlighting the importance of the policy environment in cultivating significant capital through the cooperation of different industries with varying needs, power relations, motivations and challenges. A concern, considering recognised disconnects between national and regional policy - as well as policy and industry, more generally. What remains missing within tourist studies is scholarship deconstructing the structures, interests and values drawn on in the development of food tourism policy, and the potentially limiting effects of such constructions.

\section{Conceptual framework}

In attempting to understand the ways food, class and tourism intersect, Bourdieu's (1984) concepts of cultural capital and distinction have served as particularly helpful. A Bourdieusian approach was favoured over alternative conceptualisations, because of the way his work focuses on the role of the state in classifying processes (which in turn produce class categories and experiences of class) (Dowling, 2009) - whilst also recognising the importance of agency/structure power relations. Attending to agency/structure relations was particularly productive in characterising the ways individuals are bound up in social and cultural structures, whilst simultaneously possessing potential to (re)confirm or trouble social structures - depending on their own subjectivity (class, gender, nationality and so on) and the spatial and temporal context. Alternative approaches, such as Putnam $(1993,2000)$ and Coleman $(1988,1999)$, by contrast, hold greater concern with broader social contexts - with focus granted to the ways capital affects outcomes at the scale of organisations, institutions or societies - rather than individual performance within particular social structures and contexts.

For Bourdieu (Bourdieu \& Passeron, 1990), cultural capital is the forms of knowledge, skills, education (or any form of advantage) an individual may acquire, which enables them to hold a higher status and expectation in society. 'Taste' refers to a sense that allows individuals to identify particular qualities (Fox \& Smith, 2011). Gustatory qualities of food, for instance, are bound up with class position in a way that allows groups to create, transform, defend and reproduce cultural representations around food - which are drawn on in determining basic distinctions between what is considered good and bad food. What tastes good, and why, is thus continually being made and remade, and is in constant dispute between social groups. 'Distinction' between classes is understood through two broad formulations. On the one hand, distinction occurs through competition for capital between social agents, located in stratified, segmented groups. On the other hand, distinctive taste formulations arise through ingrained dispositions, or 'habitus', where social structures and status distinctions are reproduced unconsciously by individuals (Bourdieu, 1984). A Bourdieusian approach is thus concerned with unpacking the entanglement of the individual, power relations and social structures.

Distinction, following Bourdieu, is mainly a middle class project - where the middle classes are in a constant struggle to reaffirm their positioning, through distinguishing themselves from working class symbols, performances and discourses. Through this process, working class symbols are marked as 'Other'; exotic, repulsive and unequal distinctions, when observed from a middle class perspective. Such symbols become objects, where the only position they can occupy is pathology (Skeggs, 2004). 
In Western societies, by way of example, while once excess weight signified wealth and status, today the ideal middle class body type is characterised as white, slender and fit, while poverty or lower social status is often associated with obesity (Fox \& Smith, 2011). This shift is relatively recent, and has received increasing attention through media and public health campaigns since the early 1990s (Knight, 2016b). Achieving a body in line with sociocultural ideals signifies education, discipline, conformity and success. To not align with such sociocultural ideals signifies failure, and is stereotyped as undisciplined, self-indulgent, unhealthy and non-conforming (Bell \& Valentine, 1997). Larger bodies, tied to low socio-economic status, are viewed as problematic - with 'fat' labelled 'the disease of poverty' through particular middle class discourses (Fox \& Smith, 2011). Food preference and food preparation methods are often drawn on in justifying the 'problem' of larger, working class bodies. Compulsive gluttony, unrefined tastes and fat bodies are linked to the unreflexive consumption of bad and fast global food (Guthman, 2003 and Knight, 2016b). It is on this view that we understand the deep fried Mars bar - a symbol, as we will show, of the Scottish working class, in its positioning as unhealthy, threatening, disgusting and all that is wrong with the nation's diet.

Working class Scot's are often framed through a perception that they possess a penchant to deep fried preparation practices (Knight, 2016a). A penchant often used to explain the link between diet related ill health and Scottish working class bodies. This is perhaps most notably recognised through Scotland's infamous association with the deep fried Mars bar - sold at the fish and chip shop mockingly positioned as both one of the nation's national dishes and synonymous with expanding waistlines (Dent, 2015 and Owen, 2004). Deep fried Mars bar narratives often play out through policy focused, media curated moral panics, where the identification of working class eating practices depicted as immoral, disgusting, uneducated and resultant in diet related ill-health serve to Other the working class bodies associated with these foods. Meanwhile, middle class consumption practices are praised, desired and promoted (Fox \& Smith, 2011). This process allows middle class identities to govern and distinguish themselves from working class consumption, practices and spaces, and fails to trouble the power, values and structures at play in determining inequality and diet related ill health.

\section{Method}

Following Fox and Smith (2011) in recognising the role of daily media in providing a crucial source of contemporary cultural and political views, we chose to undertake a media analysis. Recognising the ways media is shaped through governmental pressure and elite cultural dominance, we were particularly interested in the ways media is underpinned by the structures, values and interests of hegemonic groups (Fox \& Smith, 2011). The period 1 January 1995 (representing the year of inception for the deep fried Mars bar) to 31 May 2016 was chosen; such a large date range aimed to capture a broad array of narratives and shifting constructions. The newspaper database Factiva, returned 2,251 articles on the search 'deep fried Mars bar'. Utilising the hash tag 'deepfriedmarsbar', 5,640 Instagram posts. Searching 'deep fried Mars bar on YouTube returned 11,100 videos. At the time of writing it is not possible to access similar statistics for Twitter and Facebook without subscribing to a third party company equipped with processing social media analytics. All sources were then screened independently by both researchers, to ensure each data source related explicitly to the deep fried Mars bar, rendering a total of 2,312 sources. Working with such a large amount of material, from a broad range of sources enhanced the credibility of findings (Baxter \& Eyles, 1997). A comparison of findings with those of the few existing relevant studies, increased the confidence in the validity of the information produced - enhancing the trustworthiness of the findings. 
There are a range of interdisciplinary approaches grouped together under the term 'discourse analysis'; all of which broadly seek to understand the powers and systems of knowledge mediated through text. Certain tourist scholars have turned to Foucauldian approaches to understand the ways discursive contexts are constantly (re)figured and (re)created through individual talk, text and performance (Hannam \& Knox, 2005). By way of example, Fazito et al. (2016) employed a Foucauldian inspired discourse analysis to reveal silenced aspects of the tourism developmentmaking process. In doing so, emerging, and differing, representations of tourism development were identified, which incorporated often opposing representations of tourism development. Knox (2001), similarly utilising a Foucauldian discourse analysis, uncovered the operational power a series of institutions held in constructing and shaping varying versions of heritage in Scotland's peripheral north-east. For the present paper, Foucauldian discourse analysis was chosen because we were concerned with the power relations between structure and agency; specifically, the ways structures are generated in society, and the ways through which individual agency might trouble those broader structures. Alternative forms of discourse analysis, such as semiotic analysis, have, by contrast, been noted as limited in their ability to understand the role of agency, as possessing potential to both (re)confirm and trouble broader structures (Hannam \& Knox, 2005).

Foucauldian discourse analysis was applied to media sources to identify themes, particularly attending to time of publication, place of publications, emotive language and understandings drawn on, by both the author and quoted subjects, to make sense of Scottish food and enduring tourist interest in the deep fried Mars bar. The Foucauldian approach enabled insights into the sets of ideas individuals draw on to help make sense of the world around them. Rather than seeking to discover truth or the origin of a statement, Foucauldian discourse analysis uncovers the internal mechanisms through which certain structures and rules over statements are maintained about people, policy, food and so on, that position 'what is' as unchangeable, normal and common-sense. Priority, in utilising discourse analysis, was to focus on the effects a particular cultural text has on one's performance, speech and thought, by examining its production, social context and intended audience (Waitt, 2005). The methodological strength of this approach is thus in its ability to move beyond representation, to uncover power relations that affect the ways individuals act, feel and think.

Following Rose (2001), Foucauldian discourse analysis involved a three step process: familiarisation, coding and silences. Familiarisation involved reading and rereading texts, examining the relationships between statements, groups of statements and relations between different texts. Coding, required listing emergent themes and noting where they occur in text. Here, particular attention was granted to the ways each theme is given meaning, by whom and the particular kinds of knowledge produced through text. Incoherence and inconsistencies were granted particular attention as they pointed to potential moments were dominant discourses could be troubled. Finally, it was crucial to acknowledge who and what was missing from texts. Attending to silences underscored the social differences between people and the ways discourses are used to maintain understandings of class, food and place.

Foucauldian influenced scholars have long argued that knowledge production is influenced by the researcher's positionality (Rose, 1997). The researchers' identities are partial, fluid and constantly becoming. The first author, $\mathrm{X}$, is a woman in her late twenties of middle class and Euro-Australian background. Having relocated to Scotland in 2015, de Jong became interested in the ways particular ideas and performances around food are often utilised to make sense of identity in the British context. X's background in geography and post-structualist feminism have informed interpretations. The second author, $\mathrm{X}$, is a male in his sixties of working class and Northern English background. 
Having spent lengths of time living in various Northern English and Scottish locations, Varley is aware of how a sense of age, gender and ethnicity sustain particular ideas in varying spatial and cultural contexts. Varley's work in marketing and sociology have influenced analysis. Having contextualised this study conceptually and methodologically, we turn now to the results and discussion.

\section{Results \& Discussion}

\subsection{Distinguishing taste}

It is a pertinent time to examine Scotland's food tourism policy because, in recent years, the development of food tourism has become a strategic focus of The Scottish Government. Knight (2016b) connects this shift to the establishment of the Scottish Parliament in 1999, and the consequential establishment of public sector bodies focused on growing Scotland (rather than the broader United Kingdom). The establishment of the industry leadership body Scotland Food and Drink in 2007 generated a particular narrative around Scottish food. Following from this came the introduction of the first National Food and Drink Policy, Recipe for Success, in 2009. Previous to these events, the role of food within tourism policy was marginal. Current policy aims to position Scotland as the 'Land of food and drink', through a number of initiatives promoting local, pristine, high quality food and drink. Food tourism has thus become a prioritised government supported avenue for (primarily economic) growth in Scotland, through a number of initiatives including, but not limited to, EatScotland, Provenance on a Plate, At Your Service, A Taste for Events, and most recently, Year of Food \& Drink 2015. Scotland's Year of Food and Drink 2015 was a government program, led in partnership with EventScotland, VisitScotland and Scotland Food \& Drink, and was designed as an opportunity 'to enhance the food and drink experience for the visitor' and to 'spotlight, celebrate and promote Scotland's natural larder and quality produce to our people and our visitors' (Business Gateway, 2016).

Economic growth serves as central in Scotland's promotion of food tourism, with initiatives primarily aimed at adding value to existing products and services. For example, in enticing the tourist industry to use Scottish produce, The Scottish Government claims visitors are willing to pay up to $15 \%$ more for food labelled Scottish or regional in origin (Experiencing Scotland, 2016). Promotion of a very particular version of Scottish food, as 'natural', 'quality' and 'regional' is conceived as crucial to increasing visitor spend, and to increasing the economic strength of food tourism. In line with these understandings, a certain characterisation of Scotland as wild, untouched, and unspoilt dominates national policy discourses and images (cf. Scotland's Natural Larder, 2016 and Scottish Natural Heritage, 2016). Through a variety of media, key tourism industry bodies (such as VisitScotland) have worked to distinguish certain types of food and drink aligning with this version of Scotland. In consequence, types of food and drink perceived to not fit these constructions are absent (including the deep fried Mars bar). Indeed, in instances where undesired foods are drawn on by industry bodies, it is to reinforce distinctions between good local Scottish food and mass produced, unnatural, global food. Importantly, individual tourism businesses do not always align with the broader constructions introduced through larger industry bodies. In promoting the Year of Food and Drink 2015, Chief Executive of VisitScotland, Malcolm Roughead (Ross, 2015), stated:

With 90 per cent of visitors rating Scotland's food as good or excellent, it is clear the deepfried Mars bar is a far cry from the rich and varied culinary delights which can be enjoyed during a trip to Scotland today. In fact, our reputation for quality fare is growing, and where once the Scottish diet was the subject of ridicule, we are now widely celebrated for our outstanding natural larder, which includes fresh seafood, succulent meat, delicious soft 
fruits and world-famous spirits. The Year of Food and Drink 2015 is designed to raise awareness of our authentic dining experiences and encourage visitors, both from Scotland and further afield, to embark on their own culinary journeys.

(para. 19-20).

Later that same year, reflecting on the implementation of Year of Food and Drink, Roughhead (Event Scotland, 2015) claimed:

The Year of Food and Drink has been a great success, helping to raise the profile of Scotland's outstanding natural larder on the world stage...It has also helped to debunk any myths about Scottish cuisine being all about fizzy drinks and deep-fried chocolate bars.

(para. 19)

A process of distinction is evident here, where those with social power have worked to reposition dominant understandings of Scottish food as something to be desired, in an attempt to attract a high spending, middle class tourist. The dominant rhetoric emergent through the Year of Food and Drink worked to elevate particular foods, perceived as 'good', through ridiculing of the deep fried Mars bar. Distinction, in this context, works on the assumption that the deep fried Mars bar does not appeal to the desires of a high spending, middle class tourist.

A recognised paradox in constructing Scotland as a land of high quality, pristine food and drink is that Scottish food has historically laboured under its negative reputation (Everett, 2012 and Lochhead, 2012). The 'Scottish diet' is stereotypically understood to be high in sugar and fat, lacking in fruit and vegetables, and heavily dependent on deep frying techniques (Everett, 2009, Fuller et al., 2003 and Knight, 2016a). While the contemporary promotion of Scottish national cuisine is imagined as high quality, fresh and wild, the everyday consumption of food in Scottish homes is not. The average waist line of Scottish men is thought to have grown two inches in a decade, while two thirds of Scots are said to be overweight or obese (Lochhead, 2012). In Scotland, 'bad' eating habits are claimed to be the second major cause of ill-health and chronic disease (The Scottish Government, 2016).

Policy discourses work to reframe the paradox between Scotland's high quality food and wellpublicised low quality diet through the alignment of 'bad' diet with the working class. Member of Scottish National Party, Cabinet Secretary for Rural Affairs, Food and Environment, Richard Lochhead (The Scottish Government, 2009 and Lochhead, 2014), by way of example, has continued to emphasise links between socioeconomic status and 'bad' diet in identifying that the vegetable consumption in the poorest $20 \%$ of the Scottish population has fallen $20 \%$ since the 2008 Global Financial Crisis. Other parliamentary members regularly link poor food choices with lower socioeconomic individuals, including Patricia Gibson (HC Deb, 21 January 2016, c 1617), Flick Drummond (HC Deb, 21 January 2016, c 1624) and Geraint Davies (HC Deb, 21 January 2016, c 1615). Through these associations 'bad' food choices, resulting in diet related ill health, become representative of lower socioeconomic status - and in consequence become a separate issue from the promotion of high quality food and drink endorsed through food tourism policy (Knight, 2016b). In effect, such understandings are able to move beyond questioning the existence of 'good' food, to rather undertake moral judgments that insinuate lower socioeconomic individuals lack the cultural capital to know good food. The association of lower socioeconomic status as an indicator of all that is wrong with Scotland's diet works at a much deeper, class based moral framework. Particular food practices, and those who enact them, are judged and inevitably found wanting (Abbot \& Coles, 
2012). This association is problematic because it does not attempt to understand the underlying social and cultural structures producing classed disparities. This is all despite there being no concluding evidence that lower socioeconomic status alone leads to Scotland's high levels of diet related ill health (McCartney et al., 2011).

Scotland's food tourism and health discourses are not constructed in isolation; rather they are intimately entangled, informing and informed by each other, within a context of shifting contemporary Westernised ideas relating to lifestyle and diet. The deep fried Mars bar's absence from food tourism policy is thus not a surprise at a time when dominant health discourses seek out singular nutritional sources (such as fat or sugar) as simple and single answers to complex social dilemmas.

Processes of distinction are not confined to policy and government. Classed moral judgements are able to move beyond these confines through celebrity advocation within media spaces. As identified through the work of Knight (2016a), in such instances the deep fried Mars bar becomes used as a tool to draw explicit contrasts between the deep fried Mars bar and Scotland's high quality produce, restaurants and chefs. Scottish celebrity chef Nick Nairn, for example, has endorsed a number of government initiatives and is forthcoming in public comment regarding Scotland's perceived disconnect with good food. Speaking last year to a national newspaper, Nairn (Ross, 2015) shared:

The deep-fried Mars bar has been a millstone round the neck of Scottish cooking. It started as a bit of a joke but soon became the peg on which to hang all the ills of the Scottish diet. We have a kind of paradox here where we have one of the greatest larders on our doorstep with the greatest fisheries, wonderful agriculture, wild game and venison, but are known for the cursed deep-fried Mars bar.

(para. 16)

Scottish chef John Quigley also joined the fray, in 2012 sharing with the British Broadcasting Corporation (BBC) that he is 'not a fan' of the deep fried Mars Bar. Quigley claimed it 'tastes disgusting' and is 'doing harm to the reputation of Scottish food'. In further justifying his position, Quigley (Brocklehurst, 2012) drew technical distinctions between the deep fried Mars bar and deep frying fish for fish and chips:

If you get a good fish and make the batter correctly, the fish is actually steamed. The batter is fried but the fish is not and you can remove and throw away the batter if you want. That's not the case with the Mars bar. They are just fat and sugar and it is really hard to cook them without the caramel escaping through the chocolate.

Utilising a Bourdieusian analyses, Bell and Valentine (1997) note the educated classes generally advocate baking or grilling practices, while lower classes are more likely to fry. The celebrated legacy of battered fish in the United Kingdom troubles this distinction, requiring cultural capital in the form of scientific, material and technical knowledge to maintain divisions between deep fried fish and deep fried Mars bars. This knowledge positions Quigley as middle class, granting power to publicly judge the practice of cooking deep fried Mars bars as incorrect. Interestingly, perhaps because deep fried fish is not uniquely Scottish but rather a celebrated dish throughout Britain, the use of deep frying techniques in this context are able to transcend moral judgements to remain a celebrated dimension of British food heritage. Following their 'creation' in 1860 deep fried fish and chips became a crucial feature of working class life. Yet the dish was quickly elevated to restaurant status in 1896, losing some of its associations as the food of the poor (Panayi, 2014). Entanglements between class and fish and chips do, however, adhere (Walton, 1994). While the historical working class origins of fish and chips remain well known, contemporary interpretations are dependent on the spatial dimensions in which the dish is purchased and consumed - be it a fine dining restaurant 
or a fish and chip shop (Panayi, 2014). It is this understanding that underlines the class based distinction levelled at the deep fried Mars Bar. The practice or materiality of deep frying is not, in itself, innately disgusting or 'bad'. Rather it is the classed associations that become culturally constructed over time by those seeking distinction in regards to identity and social location, which position certain forms of deep frying as 'disgusting' while others remain acceptable. Understanding 'disgust' as an embodied project of socially constructed distinction, rather than an individual biological response, is unpacked in further detail in the final discussion section. Yet, before turning to a discussion of emotion, we first turn to examine governance of the deep fried Mars bar.

\subsection{Governance and tourism}

In July 2015, Carron Fish Bar (formerly The Haven), a chip shop in Stonehaven, Aberdeenshire was ordered by Aberdeenshire Council to remove a banner claiming it as the birthplace of the deep fried Mars bar. Council explained the banner must be removed 'for the greater good of the wider community', following consultations with a number of community organisations, which aimed to 'improve the look of Stonehaven for the benefit of residents, businesses and visitors' (BBC, 2015, para. 15). Carron Fish Bar owner Lorraine Watson (BBC, 2015) responded by suggesting the proposed plan was 'ridiculous' and that she would 'definitely not' be removing the banner because:

Thousands and thousands of tourists come from all over the world to purchase the deep fried Mars bar from the birthplace. It's an icon for Stonehaven. They stand outside under the banner with their Mars bar, smiling from ear to ear, then they go home and let their friends and family see it. We have no idea why the Council would want this banner taken down, bearing in mind it takes thousands of visitors to the town. Isn't that what we are trying to do? Aren't we trying to boost tourism in Scotland?

(para. 8)

Following international media attention and community support for the sign, Aberdeenshire Council chose to withdraw their request and apologise. In response, Watson (Brooks, 2015, para. 4) shared:

He [Aberdeenshire MP] was back-tracking and said that he hoped he hadn't caused me any inconvenience. In fact, he's done me a power of good. I've even had the Financial Times on the phone this morning and people passing the chip shop have been hooting their horns in support.

While unsuccessful, this example points to the ways through which those possessing social power seek to govern what belongs, and what does not belong, within Scotland's culinary landscape.

Despite attracting visitors internationally, the home to the deep fried Mars bar does not align with the touristic image sought by local council. This attempt to regulate and reconstruct boundaries of touristic culinary desire suggests divisions between Scotland's food tourism discourses and the food encounters many tourists actually seek whilst visiting Scotland.

This was not Carron Fish Bar's first encounter with governmentality. In 2012 Carron Fish Bar inquired into registering the deep fried Mars bar under the European Union's Protected Food Name Scheme. The scheme is designed to allow locally-produced food and drink products to have their unique heritage and character preserved (European Commission, 2016). Geographical indicators, such as the Protected Food Name Scheme, conceptually link increasing consumer demand for local, differentiated product taste with increasing pressure of environmental management - yet have also been conceived as marketing devices providing income to producers appealing to an affluent, reflexive middle class consumer (Warner, 2007). Watson (the restaurant owner) noted the time that 'This would really promote both our business and the town, and open us up to a bigger 
audience'. Mars, the British manufacturer of Mars bars, sought to distance itself following the inquiry, claiming the recipe contradicted their commitment to healthy eating (Urquhart, 2012):

We are concerned that the use and reference to our Mars brand and products may mislead the public into thinking that your [Carron Fish Bar] products are in some way associated with, or endorsed by, Mars, when this is not in fact the case. Mars has a marketing code, through which we promote a healthy, active lifestyle to consumers.

(para. 18)

In an attempt to control identification of its own self-identified 'healthy' product with that of the deep fried version, Mars lawyer's requested a disclaimer be placed on the Carron Fish Bar menu, stating: 'Mars is a registered trademark of Mars Incorporated. Our use of Mars is not authorised or endorsed by Mars Incorporated' (Urquhart, 2012). Disassociation through discourses of health suggest, at least to Mars, that the deep fried version does not represent the version of quality, local food sought through the Protected Food Name Scheme. Interestingly, following publicity generated by Watson Mar's retracted their request for a disclaimer.

\subsection{Desiring disgust}

Scottish chef John Quigley's reaction 'that's disgusting', discussed in the first discussion section, is an evocation commonly provoked in consuming the deep fried Mars bar (Golder, 2015 and Knight, 2016a). While the deconstructed elements of this food - Mars bar, batter and oil or fat - do not generally evoke the same reaction, in uniting these ingredients the deep fried Mars bar becomes 'a symbol of all that is wrong with the high fat, high sugar Scottish diet' (George, 2014). Lawler (2005, 442), extending Bourdieu's notion of distinction, connects the cultural construction of disgust with that of moral values and class location. Identifying that which is disgusting as 'part of a long-standing middle class project to distinguish [middle class individuals] as different' to that of the working class. To deem something as disgusting is to seemingly naturally assert a characterised prejudice of what is edible and what is not (Probyn, 2000). Rather than a biological reaction, disgust represents the act of pushing something away from normalised middle class practice so as not to threaten the boundaries of class location. Here disgust becomes extended to that of the consuming body - you become disgusting through the consumption of what is disgusting. As a mark of distinction, disgusting bodies are bound up with moral values, related to wider social relations (Ahmed, 2004).

Disgust is the Other of desire. Desire is the search for attainment; it represents all that aligns (and thus what one desires to attain) with normative identity and class location (Probyn, 1996). Desire is directed towards that which conforms to one's moral values. Consuming what is desired, therefore, retains classificatory systems through which normative cultural constructions are reliant. There is a dynamic interplay between desire and disgust (Probyn, 2000). To take pleasure, or illustrate desire, for that which is deemed disgusting points to a perceived violation of taste, representing an inability to appreciate what one ought to. Attending to moments of disgust therefore holds political potential for troubling hierarchical classed constructions and pointing to moments of openness. Building on these ideas, varying constructions and representations of the deep fried Mars bar can, for some tourists, provoke feelings of both desire and disgust - abjection - depending on the social and spatial context (Knight, 2016b, Kristeva, 1982 and Longhurst, 2006). Longhurst $(2001,28)$ states:

Abjection is the affect or feeling of anxiety, loathing and disgust that the subject has in encountering certain matter, images and fantasies - the horrible - to which it can respond only with aversion, nausea and distraction. Kristeva argues that the abject provokes fear and disgust because it exposes the border between self and other. 
Abjection - towards the deep fried Mars bar is evident in the experiences of many tourists visiting Scotland. The culinary practices of travellers to Scotland play an active role in co-producing the nation's culinary heritage. Yet, at the same time, travellers are positioned in a somewhat messy space both within and outside cultural classed performance. The complicated notions of Scottish food sought by tourists, therefore, possesses potential to both trouble and reinforce facile distinctions between constructions of food as either good, local and desirable or bad, global and disgusting; a complex process that continuously arose in analysis of the Instagram and YouTube sources.

By way of example, American chef and television personality Anthony Bourdain's internationally aired documentary series A Cook's Tour (2002) has been uploaded to YouTube. One episode, titled Highland Grub, featured in our results because the episode centred on Scottish food, with one segment specifically devoted to deep fried foods. The episode illustrated the uncertain positioning of the deep fried Mars bar and the ways encounters with Scotland's deep fried foods provoke the abject. Evident, as Bourdain declared (A Cook's Tour, 2002):

I'm going to eat some of that nasty fried food too, because I love that stuff. It's [deep fried Mars bar] one of those unique combinations. It's chocolate, it's sweet, it's everything you want.

Meeting later in the segment with an unnamed chef and friend, dialogue turned to the facile distinctions of Scottish food - where, in this touristic context, deep fried food becomes reconstructed as 'fun', through its positioning as both desired and disgusting. At the same time, however, to enable this positioning of the deep fried Mars bar, clear distinctions are maintained between fried food and 'quality' produce:

Anthony's friend: I don't want people to come here and think they're going to eat tonnes of fried food but on the other hand, when you want it you got it. We've got it when you need it but we've also got fantastic, Scotland's got fantastic salmon, some of the best meat in the world and game.

Anthony: And the scallops.

Anthony's friend: Incredible scallops and seafood. So don't get the wrong impression. This is the fun stuff.

The dynamic interplay between desire and disgust further dovetails with touristic representations of the deep fried Mars bar across the spaces of Instagram. The greater number of Instagram posts drew on discourses around first time touristic encounters with the deep fried Mars bar. Presented here are just four examples taken from the thirteen posts uploaded in the three-day period between 8 May 2016 and 12 May 2016:

John: Have you ever tried a deep fried Mars bar? It's certainly not 'fine dining' but you get all the sugar you need. It's fascinating and repulsive at once \#visitscotland \#newhaven \#scotlandsbeauty \#deepfriedmarsbar \#nikond90 \#nikon \#scotlandlover \#food \#restaurant \#worldfamous (Instagram, 12 May, 2016) 
Jessica: Ok..so I've heard about these on a million travel shows that went to Scotland. I know it's not vegan....but who wouldn't try this? I have a feeling it will be disgustingly rich but irresistible nonetheless. It's a must try. \#triptoscotland \#deepfriedmarsbar \#scottishheritage \#scottishvacation \#scottish \#scottishroots \#adventureawaits \#adventure \#travelinbug \#travel \#travelabroad \#europeanvacation \#europevacay \#greatbritain \#unitedkingdom \#uk \#ukvacay \#restlessspirit \#restlesssoul \#hippiechick \#hippie \#freespirit \#vacay (Instagram, 9 May, 2016)

Daniel: Deep Fried Mars Bar. Because when your [you're] in Edinburgh, you just have to... \#deepfriedmarsbar \#edinburgh \#grassmarket \#surprisinglytasty

Shane: Verdict??

Jean: Couldn't try that it sounds disgusting

Daniel: @shane delicious! Warm melted mars bar? What's not to like?! And I'm surprised at you @jemmer you have to be open to trying new things!

(Instagram, 11 May, 2016)

Matt: \#deepfriedmarsbar \#bucketlist \#ticked \#wheninrome \#Edinburgh \#boysgetaway \#latergram \#muchlatergram

Giles: It exists! And?

Russ: Proof that whomever says that our Scottish cousins aren't sophisticated foodies at heart are plainly fools... :-:)

Dylan: Newest bucket list addition

Tina: No just no!

Matt: @giles Sweet! In every sense.

(Instagram, 8 May, 2016)

Publicly verifying consumption whilst travelling, through the use of social media, plays a crucial role in attaining a distinctive, cosmopolitan capital (Molz, 2007). These Instagram posts offer insight into the ways the cultural discourses of travel and encounters with other cultures are represented. Through these Instagram posts we can begin to understand the ways consumption of the deep fried Mars bar during travel is framed as gastronomic adventure - where adventure represents a desire, and openness, to consume what is different, challenging and rare ('It exists!'). Difference here delineating what the tourist is not; the Other, the exotic, the strange. Both Heldke (2003) and Molz (2007) identified that 'food adventurers' are for the most part middle classed, where opportunity to travel voluntarily and expend finances on eating for fun produce difference, novelty and Otherness in relation to the privilege that a middle class position affords. Consuming the Other represents a 
moment of openness to what is different to themselves. It is a search for contrasts rather than uniformity; a performance representing transgression of cultural norms and possibility for change.

The element of surprise expressed on social media ('surprisingly tasty', 'fascinating') further points to transgression - where the experience of consumption conflicts with, and thus brings into question, the constructed representation of the deep fried Mars bar. Surprise offers new corporeal connections between tourist and working class Scot beyond normative classed judgement as formed through media circulated policy discourses. Attending to instances such as these, where tourists play a role in constructing Scottish culinary heritage, presents productive opportunity to work outside of the classed moral judgement systems through which Scotland's food tourism policy is framed. Importantly, however, consumption of the Other is dependent on difference between middle class tourist and working class Scot, ensuring the touristic encounter can be framed as adventure. Such encounters of difference are collected, becoming cultural capital that is promoted publicly - through spaces such as Instagram. Therefore, whilst offering opportunity to transgress and move beyond Scotland's dominant middle classed norms, attending to touristic consumption of the deep fried Mars bar as a form of adventure is reliant upon, and therefore simultaneously reinscribes, boundary divisions between the tourist body and the Scottish working class body.

\section{Conclusion}

Recent calls have emerged from this journal for more critical deconstructions of the political and economic structures that shape tourism policy and planning (Dredge \& Jamal, 2015). Taking up this call, we have attempted to unpack some of the values, structures and interests underpinning Scotland's food tourism policy. Through policy and media analysis, we illustrated the ways Scotland's tourist policy landscape privileges the cultural symbols of the middle class, whilst marginalising particular foods positioned as working class, through the promotion of Scottish food. This is particularly evident through the example of the deep fried Mars bar - where, despite the deep fried Mars bar's mixed representation as both a local and global food, through classed policy and media discourses it becomes constructed as global, bad and disgusting, and therefore an embarrassment to official tourism bodies. In discussing the ways health and class intersect within the Scottish tourism context, we illustrated how this framing of the deep fried Mars bar as bad is problematic because it devalues, marginalises, ridicules and Others perceived working class consumption practises.

Deconstruction of the classed dimensions of tourism policy is particularly pertinent because discussions of class are notably absent from the tourism literature; this is despite recognition that historically tourism policy and planning processes have been dominated by middle class voices, and that tourists themselves are predominantly drawn from those same classes (Dredge \& Jamal, 2015 and MacCannell, 2013).

For the tourist, Scotland offers a moment of transgressive possibility, where cultural norms are brought into question through consumption of Othered foods, such as the deep fried Mars bar. In exploring these transgressions, this paper aimed to illustrate how consuming the deep fried Mars bar offers a moment of re-evaluation, where particular classificatory systems dominating taste and tourism discourses are troubled. Such transgressions bring into question dualistic dichotomies including local/glocal, good/bad, spectacular/the everyday and desire/disgust. At the same time, however, desire to transgress classificatory systems is here dependent on the re-inscription of the Other - where desire only exists because the deep fried Mars bar is framed as a form of abject adventure. Yet, a focus within policy discourse on high quality, good food overlooks the complexity of these touristic desires, where tourists often seek out encounters with the chippy, and the deep fried Mars bar, as part of their Scottish experience. In terms of practical implications, these findings 
suggest a need for policy makers to turn attention to the complexities of tourist's culinary encounters, which point to potentially missed opportunities in promoting the nuances of the Scottish food landscape. Such nuances, experienced during travel hold political potential in their openness to cultural difference. The complexity of these understandings remain absent, so long as policy makers remain focused on the economics of attracting a perceived, high spending middle class tourist.

To that end, these findings point to the problems in perceiving food tourism as merely a means for economic development. In such instances, there is a danger that 'national cuisine' becomes essentialized and valued as a means through which to increase the tourist spend - rather than, for example, a messy, holistic and sensorial experience facilitating a myriad of classed, gendered, aged, raced (and so on) encounters that provide an entry point to the complexities of cultural foodscapes. This paper, therefore, points to the need for tourism policy officers and planners to recognise the complexities of touristic desires.

Further to this, we suggest that there are potentially many foods that become absent through processes of distinction in tourism policy and planning; in spite of touristic desires to consume, and thus embody, the Other. Scotland, for example, is not alone in experiencing increasing diet related ill-health. Across the Global North populations are said to be getting larger and less active. Media circulated moral panics render pressure to answer these concerns with single issue responses - such as seen across Australia, New Zealand, North America, as well as the United Kingdom, for example, with the 'war on sugar' (Dingle, 2014, Edwardes, 2015 and McGrath, 2016). The simplification of these discourses through single issue responses not only overlooks the complexities of this contemporary cultural dilemma, it further generates impetus to distinguish and exclude specific foods perceived to embody all that is wrong with a populations' ill-health. As is the case in Scotland, tourism policy and planning is thus potentially bound up with a myriad of contemporary health and lifestyle discourses, which arguably influence what is and what is not promoted in national culinary representations across the Global North. This study thus offers a productive start in pointing to the marginalising and silencing effects tourism policy exerts if the power values and interests involved in its formation are not critically appraised.

There are, however, a number of limitations to the present study. Primarily, in examining intersections of class, food and tourism policy, we have prioritised text and discourse over performance and embodiment. Attending to performativity would present opportunity for greater insights relating to how bodies are both inscribed by discourse, whilst also able to spatially perform both normative and transgressive identity practices. A focus on performativity would further enable a response to the second major limitation; that is, in focusing on media sources the paper is predominantly an examination of middle class voices; in consequence minimal space has been granted to the experiences, performances and discourses of working class identifying individuals. As such, understandings of class, food and tourism policy offered in this paper are partial. This paper, therefore, serves as a methodological starting point for further research examining the critical deconstruction of the values, ideas and structures bound up in food tourism policy.

\section{References}

Abbots, E. \& Coles, B. (2013). Horsemeat-gate. Food, Culture and Society, 16(4), 535-550.

A Cook's Tour. (2002). Season 1 Episode 21 Highland Grub. Food Network, 12 July.

Alkon, A. (2013). The socio-nature of local organic food. Antipode, 45(3), 663-680. 
BBC. (2015). 'Birthplace of the Deep Fried Mars Bar' Banner is Banned. Retrieved March 9, 2016, from http://www.bbc.co.uk/news/uk-scotland-north-east-orkney-shetland-33588382.

Baxter, J. \& Eyles, J. (1997). Evaluating qualitative research in social geography: establishing 'rigour' in interview analysis. Transactions in the Institute of British Geography, 22, 505-525.

Bell, D. \& Valentine, G. (1997) Consuming Geographies: We Are What We Eat. London: Routledge.

Bessiere. J. (1998). Local development and heritage: traditional food and cuisine as tourist attractions in rural areas. Sociologica Ruralis, 38(1), 21-34.

Booth, M. (2013). The Okinawa Diet: Could it Help You Live to 100? Retrieved May 17, 2016, from http://www.theguardian.com/lifeandstyle/2013/jun/19/japanese-diet-live-to-100.

Born, B. \& Purcell, M. (2009). Food systems and the local trap. In Inglis, D. \& Gimlin, D. (eds.) The Globalisation of Food, Oxford: Berg.

Bourdieu, P. Trans Nice, R. (1984). Distinction: A Social Critique on the Judgement of Taste. Cambridge: Harvard University Press.

Bourdieu, P. \& Passeron, J. (1990). Reproduction in Education, Society and Culture. London: Sage.

Brocklehurst, S. (2012). Deep-fried Mars bar: a symbol of a nations diet? Retrieved May 13, 2016, from http://www.bbc.co.uk/news/magazine-19463119.

Brooks, L. (2015) Scottish chip shop owner beats council over 'ban' on deep-fried Mars bar sign. Retrieved May 13, 2016, from http://www.theguardian.com/uk-news/2015/jul/20/scotlandchip-shop-deep-fried-mars-bar-birthplace-beats-council.

Business Gateway. (2016). Year of Food and Drink 2015. Retrieved May 13, 2016, from http://www.bgateway.com/news/year-of-food-and-drink-2015-events-fund-opens.

Campbell, A. \& MacRae, R. (2012). Local Food Plus: the connective tissue in local/sustainable supply chain development. Local Environment, 18(3), 557-566.

Cohen, E., \& Avieli, N. (2004). Food in tourism: Attraction and impediment. Annals of tourism Research, 31(4), 755-778.

Coleman, J. (1988). Social capital in the creation of human capital, American Journal of Sociology, 94, Supplement: S95-S120.

Coleman, J. (1990). Foundations of Social Theory. Cambridge: The Balknap Press of Harvard University Press.

Costa, L. \& Besio, K. (2011). Eating Hawai'i: local foods and place-making in Hawai'i regional cuisine. Social \& Cultural Geography, 12(8), 839-854.

Dent, G. (2015). Who Can Blame the Scottish for Trying to Distance Themselves from the Deep Fried Mars Bar? Retrieved May 13, 2016, http://www.independent.co.uk/voices/comment/whocan-blame-scotland-for-trying-to-distance-themselves-from-the-deep-fried-mars-bar10402948.html.

Dibb, S. \& Fitzpatrick, I. (2014). Let's Talk About Meat: Changing Dietary Behaviour for the $21^{\text {st }}$ Century. Retrieved May 13, 2016, from http://www.eatingbetter.org/uploads/Documents/Let'sTalkAboutMeat.pdf. 
Dingle, S. (2014). War on Sugar: Food Industry Likened to Big Tobacco in Debate Over Whether Sugar Causes Obesity. Retrieved: June 26, 2016, from http://www.abc.net.au/news/2014-0110/food-industry-likened-to-tobacco-firms-in-debate-over-harm-of-s/5195042.

Douglas, M. (1966). Purity and Danger: An Analysis of Concepts of Pollution and Taboo. London: Routledge.

Dowling, R. (2009). Geographies of identity: landscapes of class. Progress in Human Geography. 33(6), 833-839.

Dredge, D. \& Jamal, T. (2015). Progress in tourism planning and policy: A post-structural perspective on knowledge production. Tourism Management, 51, 285-297.

Edwardes, C. (2015). Jamie Oliver's Big Campaign for the War on Sugar. Retrieved June 16, 2016, from http://www.nzherald.co.nz/lifestyle/news/article.cfm?c id=6\&objectid=11504972.

European Commission. (2016). Agriculture and Rural Development: Geographical Indications and Traditional Specialities. Retrieved May 12, 2016, from http://ec.europa.eu/agriculture/quality/schemes/index en.htm.

Event Scotland. (2015). Toast to a Year of Food and Drink. Retrieved May 13, 2016, from http://www.eventscotland.org/news/whats-new/food-and-drink-news?page=all.

Everett, H. (2012). Food, class and the self: seal flipper pie and class conflict. In Steward, R. \& Korol, S. (eds.), Food for Thought: A Multidisciplinary Discussion. Sydney: Cape Breton University Press, 71-91.

Everett, H. (2009). Vernacular health moralities and culinary tourism in Newfoundland and Labrador. Journal of American Folklore, 122(483), 28-52.

Everett, S. (2012). Production places or consumption spaces? The place-making agency of food tourism in Ireland and Scotland. Tourism Geographies. 14(4), 535-554.

Everett, S. \& Aitchison, C. (2008). The role of food tourism in sustaining regional identity: a case study of Cornwell, South West England. Journal of Sustainable Tourism16(2), 150-167.

Everett, S. \& Slocum, S. (2013). Food and tourism: an effective partnership? A UK based review. Journal of Sustainable Tourism, 21(6), 789-809.

Experiencing Scotland. (2016). Why Offer Scottish Food and Drink? Retrieved May 13, 2016, from http://www.experiencingscotland.com/.

Feagan, R. (2007). The place of food: mapping out the 'local' in local food systems. Progress in Human Geography, 31(1), 23-42.

Featherstone, M. (1987). Lifestyle and consumer culture. Theory, Culture \& Society, 4(1), 55-70.

Fox, R., \& Smith, G. (2011). Sinner Ladies and the gospel of good taste: geographies of food, class and care. Health \& Place, 17, 403-412.

Fuller, T., Backett-Milburn, K. \& Hopton, J. (2003). Healthy eating: the views of general practitioners and patients in Scotland. The American Journal of Clinical Nutrition, 77(4), 10435-10475.

George, R. (2014). Footsteps in the Summer: Diary of an Epic Walk of Discovery Across Britain. Matador: United Kingdom. 
Golder, J. (2015). Not Just the Brave: Scotland's Culinary History. Retrieved April 13, 2016, from http://www.stuff.co.nz/travel/destinations/uk-and-ireland/74615158/Not-just-for-the-braveScotlands-culinary-history.

Gray, A. (2013). No Horsemeat Please, We're British. Retrieved January 1, 2016, from http://www.theguardian.com/commentisfree/2013/feb/08/no-horsemeat-please-british.

Guthman, J. (2003). Fast food/organic food: reflexive tastes and the making of 'yuppie chow'. Social \& Cultural Geography, 4(1), 45-58.

Halfacree, K. (2007). Trial by space for a 'radical rural': introducing localities, representations and lives'. Journal of Rural Studies, 23(2), 125-141.

Hannam, K. \& Knox, D. (2005). Discourse analysis in tourism research a critical perspective. Tourism Recreation Research. 30(2), 23-30.

Heldke, L. (2003). Exotic Appetites. London: Routledge.

Hjalager, A. \& Richards, G. (2011). Tourism and Gastronomy. London: Routledge.

Kim, Y. G., Eves, A., \& Scarles, C. (2009). Building a model of local food consumption on trips and holidays: A grounded theory approach. International Journal of Hospitality Management, 28(3), 423-431.

Knight, C. (2016a). Negative stereotypes of the Scottish diet: a qualitative analysis of deep-fried Mars bar references in bestselling newspapers in Scotland, 2011-14. Appetite, 103, 369-376.

Knight, C. (2016b). Deep-frying the nation: communication about Scottish food and nutrition. In McWilliams, M. (ed.) Food and Communication: Proceedings of the Oxford Symposium on Food and Cookery 2015. Devon: Prospect Books.

Knox, D. (2001). Doing the Doric: the institutionalisation of regional language and culture in NorthEastern Scotland. Social and Cultural Geography, 2(3), 115-130.

Kristeva, J. Trans. Roudiez, L. (1982). Powers of Horrors: An Essay on Abjection. New York: Columbia University Press.

Lawler, S. (2005). Disgusted subjects: the making of middle-class identities. The Sociological Review, 53(3), 429-446.

Lochhead, R. (2014). Food Secretary Speech on Food and Drink Debate. Retrieved May 13, 2016, from http://news.scotland.gov.uk/Speeches-Briefings/Food-Secretary-speech-on-Food-andDrink-Debate-127d.aspx.

Long, L. (2015). The Food and Folklore Reader. London: Bloomsbury.

Longhurst, R. (2006). A pornography of birth: crossing moral boundaries. ACME, 5(2), 209-229.

Longhurst, R. (2001). Bodies: Exploring Fluid Boundaries. London: Routledge.

Longhurst, R. \& Johnston, L. (2016) Dishing up difference: assemblage of food, home and migrant women in Hamilton, Aotearoa New Zealand. In Slocum, R. \& Saldanha, A. (eds.) Geographies of Race and Food: Fields, Bodies and Markets. London: Routledge.

Lund, A. (2015). Magic mussels: ingredients for improvising a tourism destination. Journal of Gastronomy and Tourism. 1, 19-31. 
MacCannell, D. (2013). The Tourist: A New Theory of the Leisure Class. United States: University of California Press.

Mak, A., Lumbers, M. \& Eves, A. (2012). Globalisation and food consumption in tourism. Annals of Tourism Research. 39(1), 171-196.

McCartney, G., Collins, C., Walsh, D. \& Batty, D. (2011). Accounting for Scotland's Excess Mortality: Towards a Synthesis. Retrieved April 13, 2016, from http://www.gcph.co.uk/assets/0000/1080/GLA147851 Hypothesis Report 2 .pdf.

McCurry, J. (2013). Tokyo's Traditional Diet. Retrieved May 17, 2016, from http://www.theguardian.com/lifeandstyle/2013/jun/19/tokyo-traditional-diet.

McGrath, M. (2016). How the War on Sugar Could Affect Coke and Pepsi's Bottom Lines. Retrieved: 23 June, 2016, from http://www.forbes.com/sites/maggiemcgrath/2016/05/17/how-the-waron-sugar-could-affect-coke-and-pepsis-bottom-lines/\#4427fe994cf7.

Mkono, M. (2011). The othering of food in touristic eatertainment: a netnography. Tourist Studies, $11(3), 253-270$.

Mkono, M., Markwell, K., \& Wilson, E. (2013). Applying Quan and Wang's structural model of the tourist experience: A Zimbabwean netnography of food tourism. Tourism Management Perspectives, 5, 68-74.

Molz, J. (2007). Eating difference: The cosmopolitan mobilities of culinary tourism. Space and Culture, 10(1), 77-93.

Morrison, D. \& Petticrew, M. (2004). Deep and crisp and eaten: Scotland's deep-fried Mars bar. The Lancet, 364, 2180.

Osman, H., Johns, N., \& Lugosi, P. (2014). Commercial hospitality in destination experiences: McDonald's and tourists' consumption of space. Tourism Management, 42, 238-247.

Owen, J. (2004). Deep-Fried Candy Bars: Scotland's Worst Food? Retrieved May 13, 2016, from http://news.nationalgeographic.com/news/2004/12/1227 041227 deep fried mars bars.ht $\underline{\mathrm{ml}}$.

Panayi, P. (2014). Fish and Chips: A History. Reaktion Books: United Kingdom.

Probyn, E. (1996). Outside Belongings. Routledge: New York.

Probyn, E. (2000). Carnal Appetites. Routledge: New York.

Putnam, R. (1993). Making Democracy Work: Civic Traditions in Modern Italy. Princeton: Princeton University Press.

Putnam, R. (2000). Bowling Alone: The Collapse and Revival of American Community. New York: Simon and Shuster.

Quan, S. \& Wang, N. (2004). Towards a structural model of the touristic experience. An illustration from food experience in tourism. Tourism Management, 25(3), 297-305.

Ritzer, G. (1995). Expressing America: A Critique of the Global Credit Card Society. Pine Forge Press: London. 
Rose, G. (2001). Visual Methodologies: An Introduction to the Interpretation of Visual Materials. London: Sage Publications.

Ross, S. (2015) $£ 177,000$ to Find Cost of Deep Fried Mars Bar. Retrieved May 13, 2016, from http://www.scotsman.com/news/177-000-to-find-cost-of-deep-fried-mars-bar-1-3920173.

Scotland's Natural Larder. (2016) Scotland's Natural Larder. Retrieved May 13, 2016, from http://scotlandsnaturallarder.co.uk/.

Scottish Natural Heritage. (2016). Food and Drink. Retrieved May 13, 2016, from http://www.snh.gov.uk/planning-and-development/economic-value/rural-enterprise/.

Seyfang, G. (2006). Ecological citizenship and sustainable consumption: examining local organic food networks. Journal of Rural Studies, 22(4), 383-395.

Sherriff, G. (2009). Towards healthy local food: issues in achieving Just Sustainability. Local Environment, 14(1), 73-92.

Sims, R. (2009). Food, place and authenticity: local food and the sustainable tourism experience. Journal of Sustainable Tourism, 17(3), 321-336.

Skeggs, B. (2004). Class, Self and Culture. London: Routledge.

Spang, R. (2000). The Invention of the Restaurant: Paris and Modern Gastronomic Culture. Cambridge: Harvard University Press.

Spence, J., Cutumisu, N., Edwards, J., Raine, K. \& Smoyer-Tomic, K. (2009) Relation between local food environments and obesity among adults. BMC Public Health, 9(192), DOI: 10.1186/14712458-9-192.

Staples, J. \& Klein, J. (2016). Introduction: consumer and consumed. Ethnos: Journal of Anthropology. DOI: 10.1080/00141844.2015.1107604.

The Scottish Government. (2009). Recipe for Success: Scotland's National Food and Drink Policy. Retrieved May 13, 2016, from http://www.gov.scot/resource/doc/277346/0083283.pdf.

The Scottish Government. (2016). Healthy Eating. Retrieved May 13, 2016, from http://www.gov.scot/Topics/Health/Healthy-Living/Food-Health.

Urquhart, F. (2012). Deep Fried Mars Bar Creators Hit with Letter from Chocolate Bar's Company. Retrieved February 9, 2016, from http://www.scotsman.com/news/odd/deep-fried-mars-barcreators-hit-with-letter-from-chocolate-bar-s-lawyers-1-2506861.

Waitt, G. (2005). Doing discourse analysis. In Hay, I. (ed.) Qualitative Research Methods in Human Geography. Oxford: Oxford University Press.

Walton, J. (1994). Fish and Chips, and the British Working Class, 1970-1940. Leicester University Press: England.

Warner, K. (2007). The quality of sustainability: agroecological partnerships and the geographic branding of California winegrapes. Journal of Rural Studies, 23, 142-155.

Williams, Z. (2015). Culinary Explorers Discover There's Life Yet in the Deep Fried Mars Bar. Retrieved May 13, 2016, from http://www.theguardian.com/uk-news/2015/jul/24/culinary-explorersdiscover-theres-life-yet-in-deep-fried-mars-bars. 
Yeoman, I., Brass, D., \& McMahon-Beattie, U. (2007). Current issue in tourism: The authentic tourist. Tourism Management, 28(4), 1128-1138. 